\title{
O SENTIDO DO SER-MÃE-QUE-TEM-A-POSSIBILIDADE-DE-TOCAR-O-FILHO- PREMATURO NA UNIDADE INTENSIVA: CONTRIBUIÇÕES PARA A ENFERMAGEM NEONATAL
}

The meaning of being the mother-that-has-the-possibility- to-touch-the-prematurebaby in the intensive unit: contributions for the neonatal nursing

El significado de ser la madre-que-tiene-la-posibilidad-de-tocar-al-hijo-prematuro en la unidad de cuidados intensivos: contribuciones para la enfermería neonatal

Rita de Cássia de Jesus Melo ${ }^{1}$

Ivis Emília de Oliveira Souza²

Cristiane Cardoso de Paula ${ }^{3}$

\section{RESUMO}

Estudo na abordagem teórico-metodológica heideggeriana com o objetivo de desvelar o sentido do ser-mãe que tem a possibilidade de tocar o filho prematuro na UTIN. Após aprovação foi desenvolvida entrevista fenomenológica com nove mulheres-mães. A análise compreensiva constituiu oito unidades de significação, e a hermenêutica permitiu desvelar o movimento existencial do sermãe em sua cotidianidade, nos modos de ser da inautenticidade e impessoalidade, movida pelo falatório, ambiguidade e temor, modos de ocupação. Ao compreender como sua a possibilidade de ter um filho prematuro, toca-o cautelosamente e cuidadosamente, transita para um entendimento no qual não mais se ocupa, se preo-cupa. Ao pre-ocupar, o ser-mãe estabelece a possibilidade de ser-aí-com-o-filho. Foi possível entender este modo de ser mãe, no qual passa por estágios antes de ver o bebê como seu e confiar em si. Possibilitar que toque seu filho, compreendendo-a em sua individualidade, singularidade, mostrou-se como um cuidado ao RNP em sua complexidade como ser-aí.

Palavras-chave: Recém-nascido prematuro. Terapia intensiva neonatal. Interação mãe-filho. Enfermagem.

\begin{abstract}
Study in the approach theorical-methodological heideggerian with the objective to reveal the meaning of being-mother that has the possibility to touch the premature baby in the Neonatal Intensive Care Unit. After approbation, was developed a phenomenological interview with nine women-mothers. The comprehensive analysis constituted eight units of significance, the hermeneutics allowed to reveal the existential movement of being-mother in the daily routine, in the ways of being of the inauthenticity and impersonality, moved by the talk, the ambiguity and fear, modes of occupation. By understanding how yours the possibility to have a premature baby, touch it gingerly and carefully, transits to an understanding in which no longer engages yourself, concerns yourself. By concerning yourself, the being-mother establishes the possibility of being-there-with-the-baby. Was possible to understand this way of being mother, in which pass by stages before seeing the baby like yours and to trust in yourself. Enable to touch the baby, understanding it in its individuality, uniqueness proved to be a care to the premature newborn in their complexity as beingthere.
\end{abstract}

Keywords: Infant, Premature. Intensive Care, Neonatal . Motherchild interaction. Nursing.

\section{Resumen}

Estudio en el enfoque teórico-metodológico heideggeriana con el objetivo de revelar el sentido del ser la madre que tiene la possibilidad de tocar el hijo prematuro en una Unidad de Cuidados Intensivos Neonatal. Después de la aprobación, fue desarrollada una entrevista fenomenológica con nueve madres. El análisis comprehensivo constituyó ocho unidades de significación, la hermenéutica permitió revelar el movimiento existencial del ser madre en su cotidianidad, en los modos de ser de la falta de autenticidad e impersonalidad, movida por el chisme, la ambigüedad y miedo, modos de ocupación. Al comprender como de ella la posibilidad de tener un bebé prematuro, lo toca con cautela y cuidado, transita para un entendimiento en el cual no más se ocupa, se preocupa. Al preocuparse, el ser madre establece la posibilidad de ser-ahícon-el-hijo. Fue posible entender este modo de ser madre, que pasa por etapas antes de ver al bebé como suyo y confiar en sí. Posibilitar el toque en el hijo, comprendiéndola en su individualidad, singularidad que se mostró como un cuidado al recién nacido prematuro en su complexidad como ser-ahí.

Palabras-clave: Prematuro. Cuidado Intensivo Neonatal. Interacción madre-hijo. Enfermería.

\footnotetext{
${ }^{1}$ Enfermeira, Especialista em Enfermagem Neonatal. Mestre em Enfermagem pela Escola de Enfermagem Anna Nery (EEAN) da Universidade Federal do Rio de Janeiro. Membro do Núcleo de Pesquisa de Enfermagem em Saúde da Criança e do Adolescente (NUPESC). Niterói - RJ. Brasil. E-mail: cassiajmelo@yahoo.com.br; ²Enfermeira, Doutora em Enfermagem. Titular de Enfermagem Obstétrica do Departamento de Enfermagem Materno Infantil da EEAN - UFRJ. Rio de Janeiro- RJ. Brasil. E-mail: ivis@superig.com.br ;' Enfermeira, Especialista em Enfermagem Pediátrica. Doutora pela Escola de Enfermagem Anna Nery da Universidade Federal do Rio de Janeiro/RJ. Docente no Departamento de Enfermagem - Centro de Ciências da Saúde da Universidade Federal de Santa Maria. Líder do Grupo de Pesquisa Cuidado à Saúde das Pessoas, Famílias e Sociedade - UFSM. Santa Maria-RS. Brasil. E-mail: cris_depaula1@hotmail.com
} 


\section{INTRODUÇÃO}

No Brasil, o modelo de atenção à saúde dos recémnascidos (RN) passou por um expressivo desenvolvimento científico, contemplando o aparato tecnológico de equipamentos, instrumental e instalações físicas, além das técnicas e procedimentos utilizados na assistência. Teve como determinante o desenvolvimento socioeconômico, político e cultural e como resultado a viabilidade de neonatos antes inviáveis".

As ações assistenciais são prestadas com vistas a atender as necessidades do RN de modo integral e singular, minimizando ou eliminando efeitos possíveis de danos a sua saúde, zelando não apenas pela sua sobrevida, mas por uma vida com qualidade. Esses avanços têm possibilitado a investigação das habilidades e competências do RN e a identificação de sinais precoces de sofrimento, assegurando, assim, um melhor prognóstico².

Muitas são as causas de internação de um RN na Unidade de Terapia Intensiva Neonatal (UTIN), sendo a prematuridade a mais prevalente. São considerados recémnascidos prematuros (RNP) aqueles nascidos antes de 37 semanas de gestação, independente do peso de nascimento, de modo que quanto menor a idade gestacional e o peso do bebê, maior a possibilidade de internação em uma UTIN².

A internação do RNP na UTIN pode provocar desestruturação do núcleo familiar, decorrente do nascimento do prematuro, por ser um acontecimento inesperado na vida de uma família. Mesmo quando é permitida a aproximação dos pais ao filho internado, há diferentes reaç̃̃es perante a situação vivenciada. Algumas mães parecem se entregar completamente ao filho, mantendo um intenso envolvimento. Porém, a maioria desenvolve um processo mais lento, expresso por insegurança, medo, tristeza, ansiedade, sentimentos de culpa e, por vezes, de rejeição, desencadeado pelo risco da morte do filho e pela perda do bebê imaginário, idealizado até o momento do parto ${ }^{3}$.

Com o nascimento, o contato físico intrauterino entre concepto e mãe é interrompido. Nos partos prematuros, por vezes, o RN necessita de atendimento imediato na sala de parto antes de ser encaminhado à UTIN, sendo o contato extrauterino adiado em decorrência das suas condições e de normas/rotinas institucionais. Esta separação, normalmente, é total no primeiro dia e parcial nos dias subsequentes.

Entender o RNP como um ser complexo, que necessita do contato com sua família para seu crescimento/ desenvolvimento saudáveis, é compreender que a assistência vai além dos cuidados de rotina na UTIN. Faz-se necessário implementar ações que possibilitem uma interação integralizada entre RN, pais e profissionais de saúde, com vistas a efetividade do cuidar".

Foi neste cotidiano de assistência ao RNP que as inquietações emergiram. Foi possível observar que, embora a equipe multiprofissional orientasse a família e, principalmente a mãe, sobre rotinas da UTIN e condições do bebê, elas apresentavam reações diferentes diante da possibilidade de tocar o filho. Presenciei expressões de surpresa ao saber de tal possibilidade, com início imediato do toque, outras diziam ter medo de machucar o bebê ou de tocar algo tão pequeno. Outras se mantinham caladas, escutavam as orientações e não esboçavam um só gesto, uma só palavra.

Pesquisadores apontam que manter um diálogo efetivo com os pais na UTIN ainda é um grande desafio; na maioria das vezes, a comunicação é verticalizada e informativa. Os profissionais pouco os escutam e pressupõem que as inquietações, medos e necessidades são iguais para todos. Embora seja comprovada cientificamente a importância da inserção dos pais nos cuidados ao RNP na UTIN, recebendo apoio e acompanhamento, o acolhimento não é realizado de maneira efetiva ${ }^{4-7}$.

0 desenvolvimento pelo Ministério da Saúde de política pública na área neonatal com uma visão de um novo paradigma assistencial estabeleceu a implementação sistemática de diversas atividades assistenciais no intuito de minimizar os efeitos da internação neonatal sobre os bebês, suas mães e familiares. Denominadas de tecnologias do cuidar de baixo custo ou leves, comportam um conjunto de conhecimentos referentes à produção das relações, vínculo e acolhimento e determinam alto impacto nos resultados da assistência. A humanização passa a ser um fator enfatizado nas UTIN, demonstrando um novo rumo que a assistência de saúde vem assumindo nos últimos anos ${ }^{2,8}$.

A valorização da interação da tríade profissional-mãefamília em uma perspectiva de humanização vem com o objetivo de alcançar um cuidado integralizado ao RNP dentro dessas unidades. Tal perspectiva, por vezes, não é valorizada, pois 0 processo de cuidar enfoca tecnologias sofisticadas destinadas ao suporte vital diante das condiçõ̃es clínicas dos prematuros ${ }^{8}$.

Assim, buscar entender o indivíduo em suas particularidades, diante das situações vivenciadas no cotidiano da UTIN, é valorizar a dimensão subjetiva que comporta todo ser em sua existencialidade ${ }^{8-9}$. Deste modo, localizei, no cotidiano assistencial de enfermeira em uma UTIN, o obscuro de como era para a mãe tomar ciência de que poderia tocar o seu filho prematuro na incubadora e tracei como questão nor teadora do estudo: como as mães significam a possibilidade do toque ao filho prematuro na UTIN? Ciente da importância da abordagem para a família, a opção pela mãe se justifica por ser a presença materna mais frequente dentro das UTIN, uma vez que o pai tem o tempo limitado por carga horária de trabalho e/ou pela rotina da instituição, bem como avós e irmãos que tem dias/horários determinados para visitação. Tal enfoque privilegiou compreender a mãe em um momento em que se encontrava fragilizada pela ocorrência da interrupção prematura do processo gestacional, sendo então a gestação prematura tanto para ela quanto para seu filho. 
Foi constituído o objeto de estudo: o significado para a mãe da possibilidade de tocar o filho prematuro na UTIN. Assim, a investigação teve como objetivo: desvelar, a partir dos significados maternos, o sentido do ser-mãe que tem a possibilidade de tocar o filho prematuro na cotidianidade assistencial de uma UTIN.

\section{METODOLOGIA}

Investigação de natureza qualitativa, com abordagem fenomenológica e referencial teórico-metodológico de Martin Heidegger ${ }^{10}$. Neste método, houve a possibilidade de ver a mãe em seu mundo próprio existencial, podendo entender as suas singularidades de ser-no-mundo, em uma relação de intersubjetividade, em que o principal objetivo do pesquisador é compreender os significados que os indivíduos atribuem a sua vivência ${ }^{11}$.

Após a aprovação do projeto de pesquisa pelo Comitê de Ética em Pesquisa da instituição cenários do estudo ( $N^{0}$ 54/2009), desenvolveu-se a etapa de campo. Para tal foi realizado um período de ambientação, a partir do momento que a mãe chega à UTIN para ver o filho. 0 pesquisador buscou, mediado pela empatia, por meio de uma conversa informal, conhecer um pouco sobre essa mulher, favorecendo assim uma relação empática na qual foi feito o convite para participação no estudo. Na maioria das vezes houve concordância livre e voluntária em participar. Então, foram acordados data, hora e local para a realização do encontro fenomenológico. Houve duas situações em que, na data acordada, percebeu-se alguma (im)possibilidade de encontro, devido à demanda emocional da mãe ou clínica do RNP; assim o encontro foi reagendado ou suspenso.

Cumpriu-se com a proteção dos sujeitos quanto aos princípios de: voluntariedade, consentimento livre e esclarecido, anonimato (as depoentes foram identificadas por pseudônimos de deusas gregas, conforme sua concordância), confidencialidade das informações da pesquisa, justiça, equidade, diminuição dos riscos e potencialização dos benefícios, resguardando sua integridade física-mental-social de danos temporários e permanentes.

0 cenário foi uma UTIN de um hospital universitário da rede pública do Rio de Janeiro/RJ, cadastrada na central estadual e municipal de regulação de vagas. As depoentes foram mães de RNP internados na UTIN. Foram excluídas do estudo mães portadoras de deficiência auditiva e transtornos mentais que poderiam impossibilitar a capacidade de verbalização.

Foram desenvolvidas entrevistas fenomenológicas ${ }^{12}$ com nove (09) mães, no período de março a maio de 2010. Todas as entrevistas foram gravadas em aparelho tipo MP3, conforme aceite das participantes. Em sala disponibilizada pela chefia da unidade, foi arrumado ambiente aconchegante para o encontro. A etapa de campo, concomitante à etapa de análise, mostrou quando foi alcançada a suficiência de significados, indicando o momento de findar o desenvolvimento de entrevistas ${ }^{13}$.

A partir da escuta e leitura atentiva dos depoimentos, foram desenvolvidos os dois momentos metódicos do referencial heideggeriano: a compreensão vaga e mediana (instância ôntica) e a compreensão interpretativa (instância ontológica). A instância ôntica refere-se aos fatos, na qual são percebidas e entendidas as coisas de imediato, estando relacionada à vida cotidiana. A instância ontológica procura a origem genuína que possibilita a coisa manifestar-se, podendo assim ser desvelados sentidos velados pelos significados ${ }^{10}$.

A compreensão vaga e mediana começa pela busca das estruturas essenciais (significantes), por meio do exercício de distinção entre o que se manifestou como essencial e como ocasional/acidental nos depoimentos. As estruturas essenciais constituíram as Unidades de Significação (US), revelando os significados maternos da possibilidade de tocar o filho. As US compuseram o fio condutor (conceito de ser) da compreensão interpretativa. Assim, por meio da hermenêutica, des-cobriuse alguns sentidos do ser-mãe que tem a possibilidade de tocar o filho prematuro na cotidianidade assistencial de uma UTIN. ${ }^{10}$

\section{RESULTADOS}

0 ser-mãe-que-tem-a-possibilidade-de-tocar-seu-filhoprematuro-na-UTIN tem medo porque sabe que CTIP é setor de algo grave onde não se pode entrar, ver ou tocar o bebê.

[...] quando falava CTI, pra mim eu não poder entrar aqui dentro [...] Diziam que o CTl é tudo fechado, pra mim eu não ia poder ver ela, só depois, quando tivesse alta. (Afrodite mãe de Cristal)

[...] quando recebi a notícia que ela estava no CTI pediátrico, meu coração ficou balanceado, será que tinha acontecido algo gravíssimo com ela, [...] porque eu pensei que no CTI pediátrico a gente não podia entrar, pegar a criança (Ariadne mãe de Pérola)

Ao chegar à unidade sente-se bem recebida e ajudada pelos profissionais de saúde, que foram explicando como tinha que fazer para poder tocar no seu bebê.

Cheguei na incubadora a moça me ensinou a abrir, não sabia nada, parecia que eu tinha dez mãos [ faz gesto mostrando as mãos], como pegar, tocar né? (Ananke mãe de Esmeralda)

[...] as meninas daqui passaram segurança, eu cheguei, me explicaram que podia tocar, pegar no colo, ficar conversando, fazer carinho pra ele sentir que eu estou ali, que a recuperação 
dele é melhor quando ele escuta a mãe, sente o toque dela, do pai também. (Circe mãe de Ônix)

Procura estar presente, praticamente todos os dias, ao lado do bebê e indica o tempo, em horas e intervalos, em que esteve na UTIN para vê-lo;

[...], todos os dias eu descia, via ela ali, olhava, não passava a mão com medo de transmiti algo pra ela (Sofia mãe de Safira)

[...] eu sempre estava ali, de 3/3 horas eu descia, [...], já estou aqui há 14 dias, vou fazer 15 dias amanhã (Ariadne mãe de Pérola)

[...] no decorrer dos dias que eu passo aqui [...] ficar em hospital não é nada bom. Nada melhor que a nossa casa, mas tem que esperar [...]. É bom saber que eu posso ficar aqui com ele, imagine se eu tiver que ir pra casa e deixar ele aqui (Themis mãe de Topázio)

Refere este contato como uma experiência sem palavras, de sentimentos maravilhosos e de sensações muito boas, como amor, satisfação e felicidade.

Pra mim foi uma coisa muito surpresa [...] maravilhoso. Foi uma sensação muito gostosa,

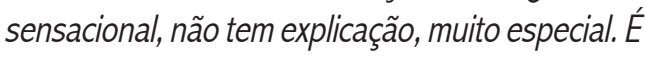
muito amor, muito amor mesmo, não tem tamanho, muito carinho, éassim tudo de bom, foi o que senti, na hora que eu toquei o meu filho [...] por mais que eu fale eu não vou conseguir falar como é que foi [... ]é uma coisa maravilhosa, não tem sensação melhor. (Ártemis mãe de Rubi)

Foi bom, muito gostoso, só que quando a gente bota a mão, já quer pegar, dá aquela tristeza, vontade de pegar, levar pra casa. (Íris mãe Ágata)

Acompanha a melhora do bebê, avaliando que está sendo bem cuidado, bem tratado e com uma aparência melhor.

[...] ela foi bem cuidada, bem tratada, a equipe é super atenciosa com as crianças, só subiu quando tiveram a certeza que estava bem. (Ariadne mãe de Pérola)

[...] eu sabia que ela estava sendo bem tratada, pois estava em boas mãos, eu ter visto aquela coisinha pequena se mexendo ali com vida. (Sofia mãe de Safira).
Entende que pode tocar, porém sendo cuidadosa e cautelosa por ser um bebê pequenininho que necessita ainda de proteção.

[...] no começo eu tive medo de botar a mão [...] você fica com medo de tocar, aífui começar a tocar nos bracinhos, nas perninhas, o dedo no peitinho, passei a mão no rostinho dele. (Ártemis mãe de Rubi)

[...] podia tocar sim, eu sabia que podia abrir a incubadora, mas eu como mãe de primeira prematura, evitei bastante vezes. (Sofia mãe de Safira)

Sente-se mais próxima do bebê, entendendo que ele sente uma força, um calor e uma energia positiva neste contato que é de troca.

[...] fui começando a me aproximar mais, de mim com ele. Então nós dois vivos, um tocando no outro, um sentindo o corpo do outro, o calor do outro. (Ártemis mãe de Rubi)

[...] passei sentir a maior química, meio diferente, que a gente sente, passei a gostar, senti um pouquinho mais ele, e até fico observando o jeito dele, que ele sente também. (Selene mãe de Quartzo)

Assim, compreende que é mãe, que o bebê que está ali na incubadora é seu (sua) filho (a) e faz parte da sua vida.

[...] acho que só de a gente ver a criança e ver que é um bebezinho que é seu,

é uma sensação muito boa, fazer o filho e não sentir seu calor é muito esquisito. (Selene mãe de Quartzo)

A primeira vez que peguei senti uma grande satisfação, eu me sentir super bem, aí eu compreendi que eu sou mãe, eu senti o toque da minha filha. (Ariadne mãe de Pérola)

A partir dessa compreensão vaga e mediana, foi possível constituir o conceito de ser-mãe-que-tem-apossibilidade-de-tocar-seu-filho-prematuro-na-UTIN, que mostra o movimento existencial a ser desvelado pela análise hermenêutica. 


\section{DISCUSSÃO}

0 ser-mãe-que-teve-a-possibilidade-de-tocar-seu-filhoprematuro-na-UTIN, ao ter passado em sua cotidianidade por um parto prematuro, recebeu a notícia que seu filho foi encaminhado à UTIN. Vive essa facticidade, ou seja, está-lançada naquilo que já está determinado e do qual não se pode escapar. "A expressão estar-lançado deve indicar a facticidade de ser entregue à responsabilidade"10:189. Sendo assim, desses fatos prematuridade e internação na UTIN - não teve escolha e não pode fugir, pois são inerentes à sua situação vivida.

Ao ter recebido esta informação ficou apreensiva, pois o que compreendia a respeito da UTIN é o que havia sido falado sobre CTI. Fala-se que o CTI é lugar de pessoas graves, com risco de morte, então o ser-mãe ficou imaginando que não poderia entrar para ver seu bebê, consequentemente a possibilidade de tocá-lo, na maioria das vezes e quase sempre, não é sequer cogitada. Assim, o ser-mãe estava no modo de disposição do falatório ${ }^{10}$.

0 falatório é a possibilidade de compreender tudo sem se ter apropriado previamente da coisa ${ }^{10}$. Quando o ser-mãe se referiu sobre a UTIN, nome determinado pela instituição hospitalar ao setor destinado ao cuidado intensivo de RNP e/ou gravemente enfermos, ela o expressou como CTI e captou o termo neonatal como pediátrico. No cotidiano, ao se falar em CTI, se reporta, quase que de imediato, à unidade de internação de pessoas com quadro clínico grave e com risco de vida, onde, outrora, regras rígidas eram determinadas. Atualmente, esses setores já apresentam rotinas modificadas, porém esse discurso permanece circulando. "As coisas são assim como são porque delas se falam assim" 10:228.

Esse falatório, ao ser repetido/repassado, se mostra como algo conhecido para o ser-mãe, que o interpretou e correlacionou à unidade onde seu filho estava internado, considerando que "o discurso comunicado pode ser compreendido amplamente sem que o ouvinte se coloque em um ser que compreenda originariamente do que se trata o discurso". Nessa concepção, o ser repete o que os outros dizem, mantendo-se numa compreensão que não é própria, por não ter adquirido o conhecimento sobre o qual se expressa, apenas apropria-se do discurso e o passa adiante ${ }^{10: 227}$.

No falatório, o ser-mãe tomou como conhecido algo que estava falando, mas que no fundo não conhecia. Nesse conhecimento falado/repetido, temia pela vida do filho que foi encaminhado para UTIN. Assim, mostrou-se dominada pelo medo da morte, algo conhecido, porém nunca vivido, apenas significado como experiência.

Sobre o temor, o temível é "sempre um ente que vem ao encontro dentro do mundo e que possui o modo de ser do manual, ou do ser simplesmente dado ou ainda da co-pre-sença"10:195. A possibilidade da mor te do filho que nasceu prematuro fez-se temível para mãe, ao ter associado que por ter sido internado na UTIN, poderia morrer.
O fenômeno do temoré analisado em três perspectivas: o que se teme, o temer e pelo que se tem $\mathrm{e}^{10}$. Para a mãe, 0 que se temia era a morte, esta que faz parte da vida de todos nós, que finda as possibilidades do ser-aí. Essa possibilidade de morte que pode chegar ou não, que pode passar ao largo, nem assim diminui, nem resolve o temor, ao contrário, 0 constitui. Teme-se por aquilo que o temor teme. A mãe temia a morte de seu filho antes mesmo de ter chegado à unidade para saber das condições do bebê. Este temoré considerado como pavor por ter como referência ser algo conhecido e familiar, que pode a qualquer momento ocorrer ou não, ao ser-no-mundo em sua cotidianidade.

Nesse modo, o ser-mãe manteve-se paralisada na impessoalidade e inautenticidade. "A pre-sença pode se comportar dessa ou daquela maneira [...] a partir de uma possibilidade própria de ser ou não ser ela mesma [...] no modo de assumir-se ou perder-se"10:39. Sendo ela mesma, assume-se na singularidade do modo de ser da autenticidade; e não sendo ela mesma, perde-se na impessoalidade do modo de ser da inautenticidade. Assim, o ser-mãe tendeu ao fechamento, esqueceu-se do sere perdeu-se no ente. Os limites de sua abertura para o mundo restringiram suas possibilidades.

Em sua facticidade de ter um filho prematuro que necessitava permanecer internado, sendo lançada no mundo da UTIN, a mãe se deparou com um ambiente novo. Por ser diferente do seu mundo circundante, que lhe é mais próximo e conhecido em seu cotidiano, o ser-mãe compreendeu-se como um estranho, não sabendo o que fazer.

Relatou que ao ter chegado à UTIN foi bem recebida pelos profissionais de saúde, sendo orientada, informada sobre como proceder para entrar na unidade e ficar junto ao seu filho. Nesse sentido, o modo mais fundamental de ser-nomundo é o se relacionar com o outro. " $\mathrm{O}$ ser-aí-com de outros é desvelado dentro do mundo para um ser-aí conosco, porque somente o ser-aí em si mesmo é essencialmente ser-com"10:38.

Nesse sentido, a solicitude é uma forma de se relacionar com o outro, de cuidar da existência do outro, que só se faz possível mediante uma relação envolvente e significante. Apresenta características básicas do ter consideração para com outro e ter paciência para com o outro. Essas são características da temporalidade ${ }^{10}$.

Os profissionais em seu cotidiano de trabalho sabem que esta mulher é mãe de um prematuro, conhecem sua história gestacional, sabem que ela não tem conhecimento de como é cuidá-lo. Assim, a recebem com paciência, orientam, explicam, ajudam, com vista que a mesma adquira segurança e habilidade para cuidar do seu filho. "O ter paciência sempre pressupõe uma expectativa de algo que possa vir a acontecer" 10:19.

Ter um filho é algo que a mulher pensa que sabe, pois faz parte do discurso cotidiano, a maioria das mulheres tem filho. Então, acha que já sabe, porém quando o tem, compreende que cuidar não é tão simples. Ter um filho prematuro é ainda mais complexo, pois exige dessa mãe uma maior compreensão 
de todo processo vivido por ela e pelo seu bebê. Nem todas as mulheres têm seu filho prematuro, e, quando têm, na maior parte das vezes, é o primeiro filho, ou o primeiro que nasce prematuro. Portanto, vivencia a novidade, pois confunde, pensa que não é novo, quando é ${ }^{10}$.

Essa relação de paciência da equipe junto à mãe fez com que se sentisse ocupada em função do bebê. Ela poderia estar na UTIN na hora que quisesse e foi informada que a sua presença e o seu toque eram importantes para o bebê, desde que fossem seguidas certas ações e rotinas informadas pela equipe. Assim, teve que fazer vários procedimentos para poder tocar o filho, guardar pertences, lavar as mãos, colocar capote, dentre outras. Ao ter recebido todas as informações e orientações, passou a estar próxima ao filho e significou estes momentos usando-os do modo cronológico, valorizou suas idas e vindas ao setor para realizar determinadas ações junto 0 bebê.

Estando presa ao manual, "mostra-se em seu ser-nomundo, empenhado nas ocupações do mundo circundante, a partir do ser que, no mundo está à mão", não compreendendo no que se ocupar propriamente. As significações expressam que o ser-mãe se ocupou do filho. Esse fenômeno determina o serem geral, em sua cotidianidade, apresentando-se no modo de ser impessoal da inautenticidade. "0 ser-aí enquanto presença ocupante mantém-se junto aquilo que cuida. [...] e sente-se enfastiado por ter que preencher o dia. [...] o tempo de repente se torna longo"10:31.

Ao se ocupar do filho, apresentou-se no modo de preocupação deficiente. Estava presa às normas instituídas pela unidade, ligada a detalhes da instância dos fatos, do manual. Esse modo de deficiência caracteriza a convivência cotidiana do ser-com. "A convivência cotidiana mantém-se entre os dois extremos da preocupação positiva - a substituição dominadora e a anteposição liberadora"10:174.

O ser-mãe, em seu cotidiano de acompanhante do filho prematuro na UTIN, expressou ambiguidade, significando sensações muito boas, maravilhosas, e, ao mesmo tempo, revelou-se dominada pelo medo: pavorde perder o filho. Parecia ter compreendido os riscos possíveis a que o prematuro estava exposto, mas ao conversar com os profissionais, se interessava, quase sempre, por saber se ganhou/perdeu peso naquele dia, visualizando questões que achava pertinentes sobre a melhora do bebê.

"Na convivência cotidiana, tanto o que é acessível a todo mundo quanto aquilo de que todo mundo pode dizer qualquer coisa vêm igualmente ao encontro, então, já não mais se poderá distinguir, na compreensão autêntica, o que se abre do que não se abre". A ambiguidade da interpretação pública proporciona discursos prévios e percepções curiosas com relação ao que acontece. "Tudo parece ter sido compreendido, captado e discutido autenticamente quando, no fundo, não foi. Ou, então, parece que não foi quando, no fundo, já foi”10:234.
0 ser-mãe apresentou-se de-caída ao ter atribuído somente aos profissionais da unidade a melhora nas condições de saúde de seu filho, absorvida pela ocupação, no mundo próprio da UTIN. Embora estivesse junto ao bebê, não conseguia compreender a importância de sua presença. Perdida no ente, vive do modo como o mundo dita que deve viver. No mundo do impessoal, do impróprio e da inautenticidade.

"O falatório, a curiosidade e a ambiguidade caracterizam o modo em que o ser realiza cotidianamente a abertura do ser-no-mundo. [...] Nelas e em sua conexão ontológica, desentranha-se um modo fundamental que denominamos com o termo de-cadência" A de-cadência indica que, na maior parte das vezes, o ser está junto e no mundo das ocupações. Constitui um modo de ser-no-mundo em que é totalmente absorvido pelo mundo e pela co-presença dos outros no impessoa/lo:236.

Querer ter filho é, na maioria das vezes e quase sempre, desejado pela mulher, em sua compreensão ao engravidar essa possibilidade será concretizada. Porém, ao ter um parto prematuro e ter seu filho internado em uma UTIN, a mãe se vê lançada na possibilidade de ter ou não o seu bebê. "É no proceder a si mesma, enquanto ser para poder-se mais próprio, que subsiste a condição ontológico-existencial de possibilidade de ser livre para as possibilidades propriamente existenciárias" 10:258.

De modo que o ser-mãe passa a se relacionar com o filho de início em suas possibilidades, na impropriedade, com base no falatório, frente ao pavor da perda e se encontrava, por vezes, na ambiguidade ${ }^{10}$.

A essência do ser em sua existência é sua possibilidade, o ser-mãe-que-tem-a-possibilidade-detocar-seu-filho-prematuro-na-UTIN teve a possibilidade de tocar ou não seu filho; por ser este caráter sempre seu, não se pode a ela nada impor ${ }^{10}$

Ao compreender sua possibilidade de tocar o filho, começa a tocar de sua maneira, cautelosamente e cuidadosamente, compreendendo o risco de melhora ou de piora do filho por ser pequeno. Dessa maneira, transita para uma possibilidade de pre-ocupação, em um movimento de autenticidade que emerge da cotidianidade. Não mais se ocupa, mas se pre-ocupa, passando a perceber nesse tocar a proximidade do bebê, a energia de troca que sente neste contato.

Ao se pre-ocupar, o ser-mãe estabelece um ser-aícom-o-filho, reconhecendo a si mesma e ao seu filho como ser-de-possibilidades. Esta compreensão direciona o sermãe a ser-com-o-filho, sendo-com-o-filho, ela se compreende sendo-mãe-de-prematuro, e assim, sendo mãe. Nesta dimensão, ela se relaciona não mais com o bebê que nasceu prematuro, mas com o seu filho, com o ser e não com o ente. 


\section{CONSIDERAÇÕES FINAIS}

Neste movimento, o ser-mãe, em sua cotidianidade, mostrou-se na inautenticidade. Movida pelo falatório, entendia que aUTIN é um lugar onde se morre. Assim, sentiu insegurança e medo que o filho morresse, desencadeando uma modalidade de temor. Este modo de disposição impedia sua compreensão dos fatos vividos, direcionando-a a ambiguidade, em que acreditava que tudo já havia sido compreendido quando na verdade ainda não tinha sido.

A equipe de profissionais de saúde da UTIN a recebeu bem, tratou-a com paciência, orientou o que tinha que fazer para chegar até o bebê e, desse modo, ficou presa às tarefas do cotidiano, modo próprio de ocupação. Creditando o cuidar do seu filho aos profissionais, esquivou-se da tarefa de ser-em-simesma, de modo que de-caiu, se alienando. Dessa maneira, agiu no modo determinado pelos profissionais, ocupou-se com horários, peso diário, parâmetros de equipamentos em uso no seu bebê.

Ao compreender sua possibilidade de tocar o filho, $\mathrm{e}$ fazê-lo ou não na singularidade de seu tempo vivido, o ser-mãe mostra-se no modo da pre-ocupação e estabelece um ser-aícom-o-filho, re-conhecendo ambos como ser-de-possibilidades. Des-vela um movimento da inautenticidade no cotidiano assistencial da UTI à autenticidade vivida pelo ser-mãe-queteve-a-possibilidade-de-tocar-seu-filho-prematuro-na-UTIN.

Diante dessa compreensão da vivência cotidiana desse ser-mãe, faz-se imprescindível que os profissionais que atuam em UTIN entendam a importância, para o bebê e sua mãe, que essa aproximação se efetive mais precocemente possível.

A partir do momento em que o ser-mãe consegue superar os sentimentos e sensações do parto prematuro, aceitando a situação atual, poderá compreender as necessidades de seu filho. A presença da mãe junto do bebê é uma forma de superar as dificuldades do nascimento do filho prematuro.

0 estudo mostrou que, para o ser-mãe, chegar até a UTIN é um momento de muita apreensão, pois fica imaginando diferentes possibilidades que terá pela frente, como estará o bebê: vivo? morto? 0 que será conversado com ela sobre seu bebê? Como é a fisionomia do seu filho que olhou tão rápido ao nascer, considerando que algumas nem o olharam? São momentos considerados por elas como intermináveis.

0 estudo também permitiu compreender que essa mãe, ao acompanhar seu filho no longo tempo de internação, sentiuse sozinha, com saudades da família e de casa. Entender que a assistência prestada na UTIN vai além do cuidado ao bebê possibilita compreender que as mães querem e precisam alguém ao seu lado. Faz-se necessário que a equipe promova um exerćíio diário de uma escuta atentiva, de ser-com-a-mãe diante das suas necessidades, para que assim o cuidado seja efetivo.

0 ser-mãe necessita de apoio, compreensão e oportunidade de comunicação para refazer seu mundo-vida, reconstruir sua cotidianidade existencial, dentro dessa nova realidade, e emergir como um ser-com-o-filho dentro da UTIN.

Este estudo, em sua hermenêutica, desvelou 0 movimento existencialque o ser-mãe-que-tem-a-possibilidadede-tocar-o-filho-prematuro-na-UTIN significou em seus depoimentos, colaborando, dessa maneira, com as evidências cientificas de benefícios do vínculo afetivo para o bebê prematuro e sua família. Foi possível entender este modo de vir-a-ser-mãe, no qual esta pode passar por estágios diferenciados antes de começar a ver o bebê como seu e confiar em si mesma. Importa, então, permitir que o veja, fique ao seu lado, o toque da sua maneira, envolvendo-se no cuidado ao seu filho.

0 toque mostrou-se como uma possibilidade relacional, de aproximação, proximidade que a mãe, de início, desconhecia. Em sua temerosidade achava que só poderia tocar seu filho no momento da alta ou fora dos aparelhos que estavam sendo utilizados em seu processo de recuperação.

Este estudo confirmou as recomendações contidas no Manual do Método Canguru, de como podemos contribuir para a formação de laços afetivos entre mãe e bebê e como possibilitar a mãe, quando possível, ver e tocar seu filho, ainda na sala de parto, antes que seja conduzido à UTIN. Nesse momento, ela ainda terá uma visão de seu bebê sem adesivos, aparelhos conectados, entre outros. Será informada para onde seu bebê está sendo levado e por quê, quais os cuidados prováveis que ele receberá na UTIN, que ela poderá vê-lo e tocá-lo, logo que se sinta em condições.

Disponibilizar um profissional da equipe que possa visitar a mãe ainda em sua unidade de internação e que transmita notícias sobre o bebê faz com que se sinta mais confiante com a equipe, e que algumas de suas inquietações sejam minimizadas ou sanadas. Outros passos estão disponíveis no manual, os quais se tornam essenciais para o sucesso da afetividade entre mãe e bebê.

Foi possível observar o quanto o falatório influencia a cotidianidade. As UTIs ainda permanecem com o estigma construído culturalmente, sendo entendidas como um lugar para a morte. A falta de informação e conhecimento prévio gera insegurança e medo, sendo o ambiente considerado assustador. É fundamental a desmitificação para que essas unidades sejam compreendidas como um ambiente de assistência especializada, onde se trabalha para a vida. A morte é uma possibilidade dos mortais.

Informar cientemente o cliente/usuário favorece a interação, fortalecendo a confiança. A inserção das tecnologias leves de produção de comunicação permite produzir relações, tendo como produtos a construção ou não de acolhimento, vínculo e responsabilização entre profissionais e o cliente/ usuário.

Repensar o cuidado de enfermagem ao RNP em uma UTIN, ambiente entremeado de diferentes tecnologias, exige atentar para as atividades do dia-a-dia, fundamentando-se não 
somente em suas peculiaridades da condição clínica de prematuridade, em um cuidado de ocupação, pautado em um cotidiano assistencial de modelos, normas e rotinas que norteiam um padrão determinado de atenção em saúde. 0 cuidado a esse RNP deve ser sustentado pela pre-ocupação, em uma forma de atuação que privilegie o bebê como ser-depossibilidades, que interage, que vive, que necessita ser-como-outro.

Garantir a essa mãe a possibilidade de se expressar, abrir espaço para o diálogo, para ouvir, disponibilizar-se, sercom, é uma tecnologia de cuidado que oportuniza expor os seus medos, inseguranças e anseios. Estimular o livre e precoce acesso da mãe à UTIN possibilita que compreenda o quanto é importante estar presente para maternar seu filho, facilitando, desse modo, uma relação passível de um movimento de intersubjetividade e, assim, ser-com-o-filho. Tais intervenções são cuidados possíveis no atendimento ao RNP em sua complexidade como ser-aí, como sujeito que objetivamente necessita de cuidados básicos e de rotina, mas também existencialmente carece de receber carinho, atenção, e ser reconhecido por sua mãe e família, o que possibilita prevenir transtornos no desenvolvimento e melhorar a qualidade de vida dos envolvidos nesse processo.

\section{REFERÊNCIAS}

1.Costa R, Padilha MI, Monticelli M. Produção de conhecimento sobre o cuidado ao recém-nascido em UTI Neonatal: contribuição da enfermagem brasileira. Rev Esc Enferm USP. 2010; 44(1): 199-04

2.LamyZC, et al. Atenção humanizada ao recém-nascido de baixo peso Método Canguru: a proposta brasileira. Cienc Saude Colet. 2005, 10(3): 659-68.

3.Bowlby J. Cuidados maternos e saúde mental. São Paulo: Martins Fontes; 2006.

4.Araújo BBM, Rodrigues BMRD, Rodrigues EC. 0 diálogo entre a equipe de saúde e mães de bebês prematuros: uma análise freireana. Rev Enferm UERJ. 2008; 16(2): 180-86.

5.Christoffel MM, Silva LR. Percepções das enfermeiras frente à dor do recém-nascido hospitalizado na UTI Neonatal. Escola Anna Nery. 2002; 6(supl1): 53-63.

6.Alves VH, et al A permanência da família em unidade de terapia intensiva neonatal: imaginário coletivo dos enfermeiros. Cienc Cuid Saude. 2009; 8(2): 250-56.

7.Reis AT. 0 significado da cirurgia neonatal na presença de mal formação congênita: A visão materna para o cuidar de enfermagem. [tese de doutorado] Rio de Janeiro: Escola de Enfermagem Ana Nery/UFRJ; 2010
8.Rocha PK, Prado ML, Wal ML, Carraro TE. Cuidado e tecnologia: aproximações através do modelo de cuidado. Rev Bras Enferm. 2008; 61(1):113-16.

9.Gorgulho FR. Tão longe, tão perto: a vivência do enfermeiro na construção da relação mãe/recém-nascido na UTIN. [dissertação de mestrado]. Rio de Janeiro: Faculdade de Enfermagem/ UERJ; 2009.

10.Heidegger M. Ser e tempo, 1. Petrópolis(RJ): Vozes; 2005.

11.Capalbo C. Considerações sobre o método fenomenológico e a enfermagem. Rev Enferm UERJ. 1994; 2(2): 192-97.

12.Carvalho AS. Metodologia da entrevista: uma abordagem fenomenológica. Rio de Janeiro: Agir; 1991.

13.Boemer MR. A condução de estudos segundo a metodologia de investigação fenomenológica. Rev Latino-Am Enfermagem. 1994 jan; 2(1): 69-82. 